\title{
Cerebral Blood Flow Alterations Associated With High Volume Caudal Block In Infants
}

\author{
P Castillo1, M Lundblad¹, J Forestier ${ }^{1}$, S Eksborg², PA Lönnqvist ${ }^{1}$ \\ 1 Paediatric Anaesthesia, Karolinska University Hospital; ${ }^{2}$ Dept of Women \& Child Health, Karolinska Institutet, \\ Stockholm, Sweden.
}

Background Major reductions of Cerebral Blood Flow Velocity (CBFV) with concomitant reduction of cerebral oxygenation have been observed after administration of high-volume $\left(1.5 \mathrm{ml} \mathrm{kg}^{-1}\right)$ caudal block in infants (1). This is due to a rostral movement of cerebrospinal fluid (CSF) caused by the caudal injection(2). That in turn will cause a substantial increase in Intracranial Pressure (ICP)(1).

The primary aim of this study was to determine at what injected volume reduction in cerebral blood flow velocity (CBFV) will start to appear. We hypothesize that this volume-blood flow relationship will be similar to the well-known ICP volumepressure curve, thus, showing a curvilinear relationship.

Methods 15 patients, 0-3 months of age where studied. Median weight of 4,9 kg $(2,1-6,4)$. Middle cerebral artery Ultrasound Doppler was performed and measurements of CBFV of the middle cerebral artery (Vmax, corresponding the peak velocity. Vmin corresponding lowest velocity. VTI, velocity time index. Pulsatility index and Resistivity index.) and hemodynamic parameters were recorded at predetermined randomized points of injection during the caudal injection.

Results: CBFV decreased in all patients. The parameter most affected was Vmin. Median velocity decrease was 48 \% (15-68). Hemodynamic parameters remained stable. There was a considerable variability between patients. Reduction of CBFV increased at approximately $20-40 \%$ of the injected volume, corresponding to a volume of 0.3-0.6 $\mathrm{ml} \mathrm{kg}^{-1}$.

Conclusion: Our data analysis show that cerebral blood flow parameters start to be more substantially affected when $>0,3 \mathrm{ml} \mathrm{kg}^{-1}$ is injected.

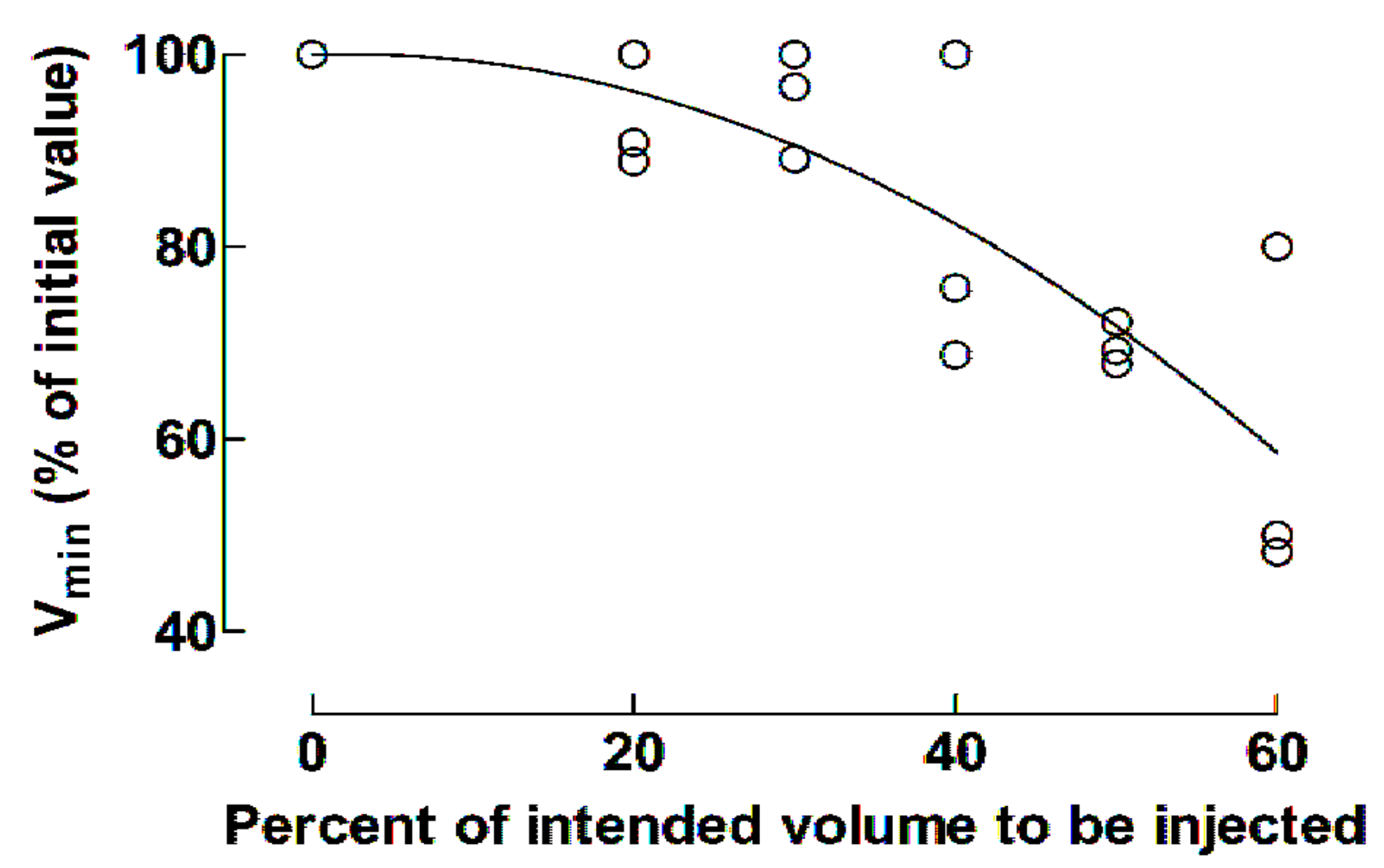

1. Lundblad M, Forestier J, Marhofer D, Eksborg S, Winberg P, Lonnqvist PA. Reduction of cerebral mean blood flow velocity and oxygenation after high-volume (1.5 ml kg(-)(1)) caudal block in infants. Br J Anaesth. 2014;113(4):688-94.

2. Lundblad M, Eksborg S, Lonnqvist PA. Secondary spread of caudal block as assessed by ultrasonography. $\mathrm{Br} \mathrm{J}$ Anaesth. 2012;108(4):675-81. 